\title{
Differential Corticosteroid Modulation of Inhibitory Synaptic Currents in the Dorsal and Ventral Hippocampus
}

\author{
Nicola Maggio and Menahem Segal \\ Department of Neurobiology, The Weizmann Institute, 76100 Rehovot, Israel
}

\begin{abstract}
Corticosterone has been known to mediate the effects of stress on cognitive functions associated with the hippocampus. Acting at mineralocorticosteroid receptors (MRs) and glucocorticosteroid receptors (GRs), corticosterone exerts several effects in the hippocampus and elsewhere. Assuming that there are major functional differences between the dorsal hippocampus (DH) and ventral hippocampus $(\mathrm{VH})$, and that these may be regulated by local interneurons, we analyzed the action of corticosterone on inhibitory synaptic currents in patch-clamped pyramidal neurons, recorded in acute slices of $\mathrm{DH}$ and VH. Corticosterone, through activation of MRs, reduced the frequency of spontaneous IPSCs in VH but not in DH neurons, and markedly suppressed paired-pulse facilitation of evoked inhibitory synaptic currents. These effects were mimicked by aldosterone, an MR agonist, and were blocked by an MR antagonist. In contrast, corticosterone caused an increase in the magnitude of IPSCs in both the DH and VH via its activation of GRs. This effect was mimicked by a GR agonist, dexamethasone, which produced a slow-onset, large potentiation reaching a peak within 45- 60 min after onset of perfusion, and was blocked by a GR antagonist. The amplitude of mIPSCs was markedly increased by the GR agonist, indicating a synaptic locus of effect. These results indicate that corticosterone has a dual action, which may underlie the differential functional effects of stress hormones in the $\mathrm{DH}$ and $\mathrm{VH}$.
\end{abstract}

\section{Introduction}

Stress has a profound time- and region-selective effect on synaptic plasticity and cognitive functions associated with the hippocampus (Kim and Yoon, 1998; Garcia, 2002; Kim et al., 2006). Corticosterone (Cort), the main stress hormone in rodents, activates two receptor types, including the high-affinity mineralocorticosteroid receptor (MR) and the low-affinity glucocorticosteroid receptor (GR). The effects of corticosterone on intrinsic and synaptic properties of hippocampal neurons, acting via both genomic and nongenomic routes, have been studied extensively in recent years [see Joëls (2008) and references therein]. For example, it has been shown that a rapid, nongenomic MR-mediated action involves a presynaptic increase in frequency of mEPSCs, but also a postsynaptic decrease in amplitude of the transient $\mathrm{K}$ current $I_{\mathrm{A}}$ (Olijslagers et al., 2008). A GR-mediated enhancement of $I_{\mathrm{Ca}}$ in these same neurons has also been reported (Chameau et al., 2007). Yet, a clear picture of the main actions of corticosterone on synaptic interactions and its relations to the ability to express LTP in the hippocampus is still missing. The fact that such an interaction is complex is illustrated in a recent study, where, following an exposure to acute swim stress, the activation of MRs produced an enhancement of LTP in the perforant path of the dentate gyrus, whereas following activation of GRs before the stressful experience an impairment in LTP was found (Avital et

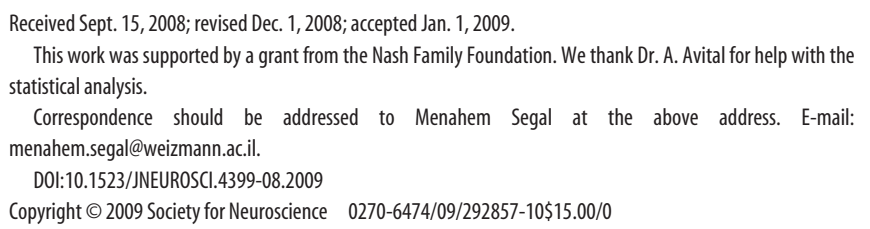

al., 2006). These studies suggest that MRs and GRs assume opposite roles in the regulation of synaptic plasticity after an acute exposure to stressors.

One major factor that may underlie the heterogeneity of effects of corticosterone is the recently described dorsoventral disparity in the functional organization of the hippocampus, such that the dorsal hippocampus is likely to encode spatial/cognitive memory, whereas the ventral sector processes information related to the affective and homeostatic state of the animal (Moser and Moser, 1998). In support of this assumption, it was shown, both in vivo (Maruki et al., 2001) and in vitro (Papatheodoropoulos and Kostopoulos, 2000; Colgin et al., 2004a; Maggio and Segal, 2007a), that the ability to evoke short- and long-term plasticity differs between dorsal hippocampus $(\mathrm{DH})$ and ventral hippocampus $(\mathrm{VH})$. Specifically, in the $\mathrm{VH}$, the magnitude of LTP was significantly smaller than that elicited in the DH. However, unlike the case in the DH, stress actually enhanced LTP in the VH (Maggio and Segal, 2007b). Several factors may underlie this difference in ability to generate LTP. One involves the presence of spontaneous rhythmic activity in the $\mathrm{VH}$, which may in and of itself disrupt the ability to express LTP (Colgin et al., $2004 \mathrm{~b}$ ). We hypothesized that the two sectors of the hippocampus possess different subarrays of corticosterone (Cort) receptors and are therefore differentially modulated via these steroid effects. We further hypothesize that the effects of Cort are exerted on GABA neurotransmission (Orchinik et al., 2001).

Using patch-clamped neurons in DH and VH slices, we explored the differential effects of corticosteroid ligands on membrane and synaptic properties of rat hippocampal neurons. The present study focuses on steroid effects on IPSCs in DH and VH. 
$\mathrm{DH}$

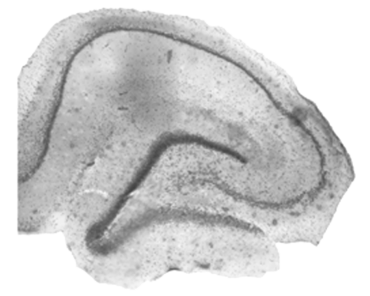

$\mathrm{VH}$

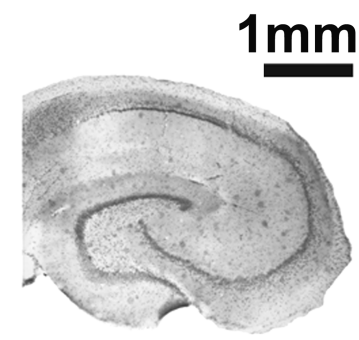

Figure 1. Morphology of dorsal and ventral hippocampal slices. Nissl-stained histological sections taken from a slice of the DH (top) and VH (bottom).

Table 1. Cellular properties of CA1 pyramidal neurons in DH and VH

\begin{tabular}{lccc}
\hline Parameter & VH $(n=12)$ & DH $(n=12)$ & $p$ value \\
\hline RMP $(\mathrm{mV})$ & $-58.45 \pm 1.33$ & $-57.79 \pm 1.25$ & 0.22 \\
Input resistance $(\mathrm{M} \Omega)$ & $43.53 \pm 1.76$ & $45.27 \pm 2.14$ & 0.0412 \\
$\tau(\mathrm{ms})$ & $25.08 \pm 1.17$ & $29.35 \pm 1.5$ & $<0.01$ \\
AP threshold $(\mathrm{mV})$ & $-34.63 \pm 1.5$ & $-42.17 \pm 2.36$ & $<0.01$ \\
AP amplitude $(\mathrm{mV})$ & $111.46 \pm 3.11$ & $113.13 \pm 2.3$ & 0.17 \\
AP duration (ms) & $3.44 \pm 0.104$ & $3.42 \pm 0.219$ & 0.760 \\
AP time to peak (ms) & $0.114 \pm 0.003$ & $0.115 \pm 0.003$ & 0.910 \\
\hline
\end{tabular}

The results illustrate a striking difference between MR- and GRmediated actions in the two sectors of the hippocampus.

\section{Materials and Methods}

The following drugs were prepared from frozen stocks and used at these final concentrations: corticosterone (30 and $100 \mathrm{nM}$ ), spironolactone (Spiro, $500 \mathrm{~nm}$ ), mifepristone [RU-38486 (RU), $500 \mathrm{~nm}$ ], aldosterone (Aldo, $10 \mathrm{~nm}$ ), dexamethasone (Dexa, 30 and $100 \mathrm{~nm})$, DNQX (10 $\mu \mathrm{M})$, APV $(50 \mu \mathrm{M})$, GABA $(5 \mu \mathrm{M})$, bicuculline $(20 \mu \mathrm{M})$, and finasteride $(1 \mu \mathrm{M})$. All drugs were purchased from Sigma. TTX $(1 \mu \mathrm{M})$ was purchased from Alomone Labs. Pharmaceuticals were added to the perfusion medium with special care to prevent changes in temperature, $\mathrm{pH}$, flow rate, or degree of oxygenation of the artificial CSF (ACSF).

Slice preparation. Animal handling was approved by the Institutional Animal Care and Use Committee, which adheres to the National law, and NIH rules. Male Wistar rats (2-3 weeks of age) were rapidly decapitated, the hippocampus was removed, and $400 \mu \mathrm{m}$ slices were prepared using a vibroslicer. Specifically, the dorsal hippocampus was identified from coronal slices as the first rostral $800-1000 \mu \mathrm{m}$ of the hippocampus at a distance of $1-1.1 \mathrm{~cm}$ from the frontal pole. The ventral hippocampus was identified in horizontal slices as the first $800 \mu \mathrm{m}$ of the hippocampus at a distance of $0.9-1 \mathrm{~mm}$ from the base of the brain. Fixed, resectioned, and Nissl-stained slice examples are shown in Figure 1. Using these slicing procedures, maximal dendritic trees of the recorded neurons and their main afferents were included within the slices, as indicated in dye-filled neurons (data not shown). All comparisons between the $\mathrm{DH}$ and $\mathrm{VH}$ were made with slices of animals derived from the same litter, age, and experimental conditions.

Electrophysiology. Slices were incubated for $1.5 \mathrm{~h}$ in a humidified, carbogenated $\left(5 \% \mathrm{CO}_{2}\right.$ and $\left.95 \% \mathrm{O}_{2}\right)$ gas atmosphere at RT and were perfused with ACSF [containing (in mM) $124 \mathrm{NaCl}, 2 \mathrm{KCl}, 26 \mathrm{NaHCO}_{3}, 1.24$ $\mathrm{KH}_{2} \mathrm{PO}_{4}, 2.5 \mathrm{CaCl}_{2}, 2 \mathrm{MgSO}_{4}$, and 10 glucose, $\mathrm{pH}$ 7.4]. Slices were then transferred to a recording chamber placed on the stage of an Olympus

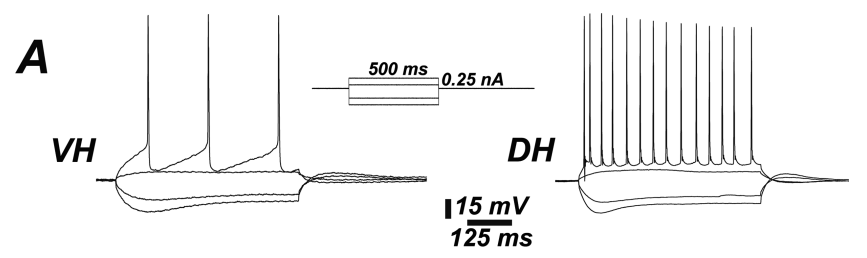

B
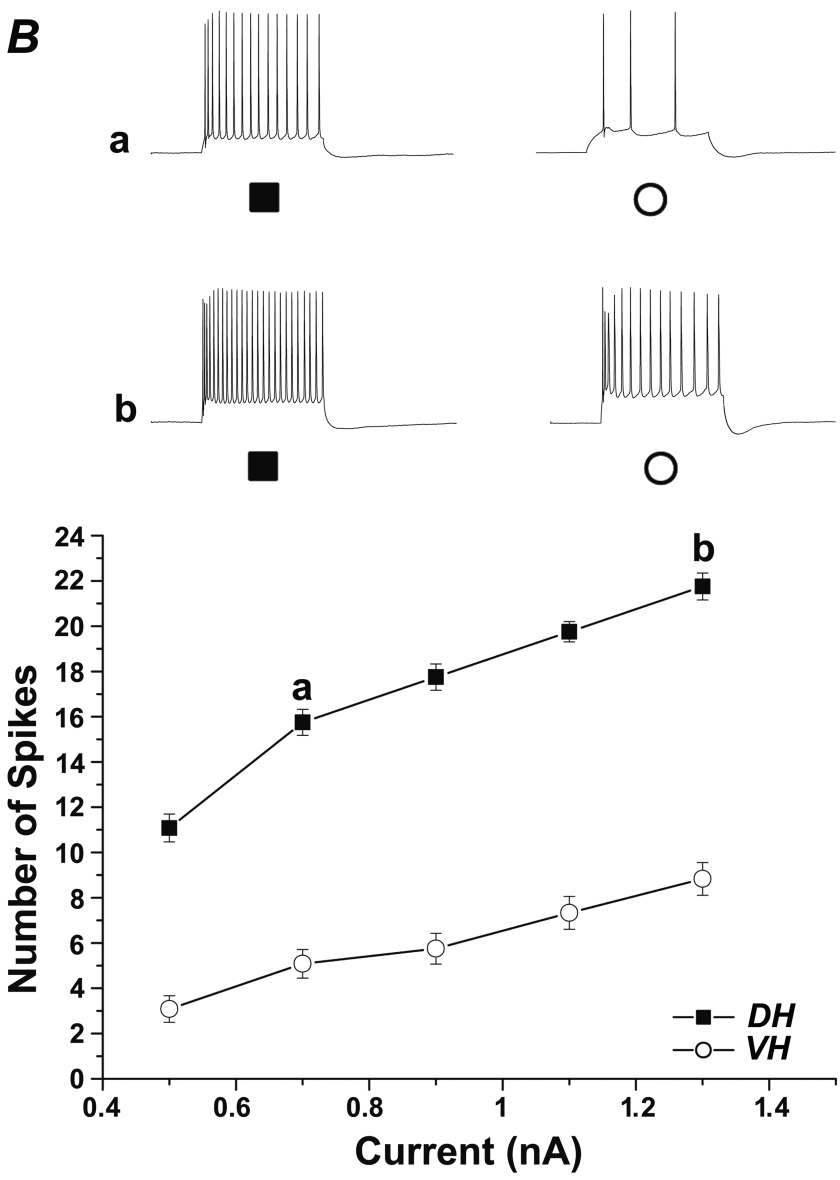

Figure 2. Cellular properties of CA1 pyramidal neurons in DH and VH. $A$, Representative traces show that step injections of same current (inset) evoked different responses in CA1 pyramidal neurons of $\mathrm{DH}$ and $\mathrm{VH} . \boldsymbol{B}$, Spike rate of $\mathrm{CA} 1$ pyramidal neurons was higher in $\mathrm{DH}$ than in VH. The number of spikes is expressed as a function of current step. Representative traces at indicated current injected $(a, b)$ are shown on top. $n=12$ cells for each region. Error bars in this and the following figures indicate SEMs.

Table 2. Cellular properties of DH neurons before and during exposure to Cort

\begin{tabular}{lccc}
\hline Parameter & Control $(n=6)$ & Treated $(n=12)$ & $p$ value \\
\hline RMP $(\mathrm{mV})$ & $-59.54 \pm 0.19$ & $-59.61 \pm 0.33$ & 0.881 \\
Input resistance $(\mathrm{M} \Omega)$ & $45.5 \pm 1.05$ & $38.41 \pm 1.14$ & $<0.01$ \\
$\tau(\mathrm{ms})$ & $29.75 \pm 0.71$ & $12.67 \pm 0.39$ & $<0.001$ \\
AP threshold $(\mathrm{mV})$ & $-40.49 \pm 0.42$ & $-41.21 \pm 0.47$ & 0.334 \\
AP amplitude $(\mathrm{mV})$ & $114.25 \pm 1.12$ & $112.64 \pm 1.74$ & 0.24 \\
AP duration $(\mathrm{ms})$ & $3.32 \pm 0.120$ & $3.40 \pm 0.150$ & 0.58 \\
AP time to peak (ms) & $0.112 \pm 0.006$ & $0.121 \pm 0.007$ & 0.41 \\
\hline
\end{tabular}

BX51WI upright microscope and perfused with ACSF at a rate that allowed a given drug concentration to fully equilibrate within $6 \mathrm{~min}$ after onset of its perfusion. Single hippocampal CA1 neurons were visualized using infrared Nomarski optics and recorded with patch pipettes containing the following (in $\mathrm{mm}$ ): $136 \mathrm{~K}$-gluconate (or $\mathrm{CsCl}$ ), $10 \mathrm{KCl}, 5$ $\mathrm{NaCl}, 10$ HEPES, 0.1 EGTA, $0.3 \mathrm{Na}$-GTP, $1 \mathrm{Mg}$-ATP, and 5 phosphocreatine, $\mathrm{pH} 7.2$, having a resistance of 5-10 M $\Omega$. Quality criteria for accept- 


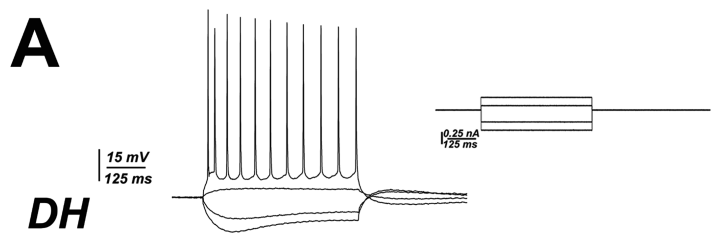

Control
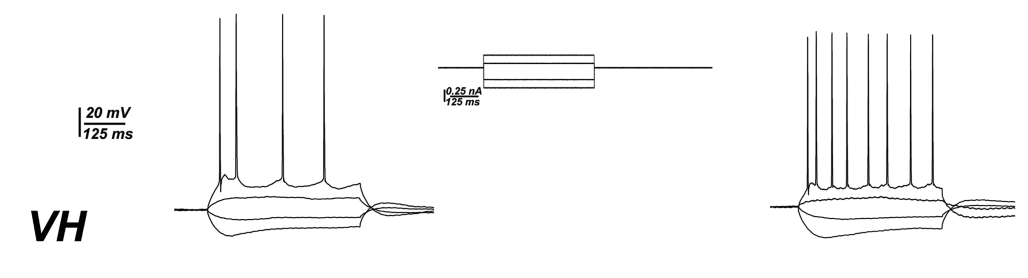

B
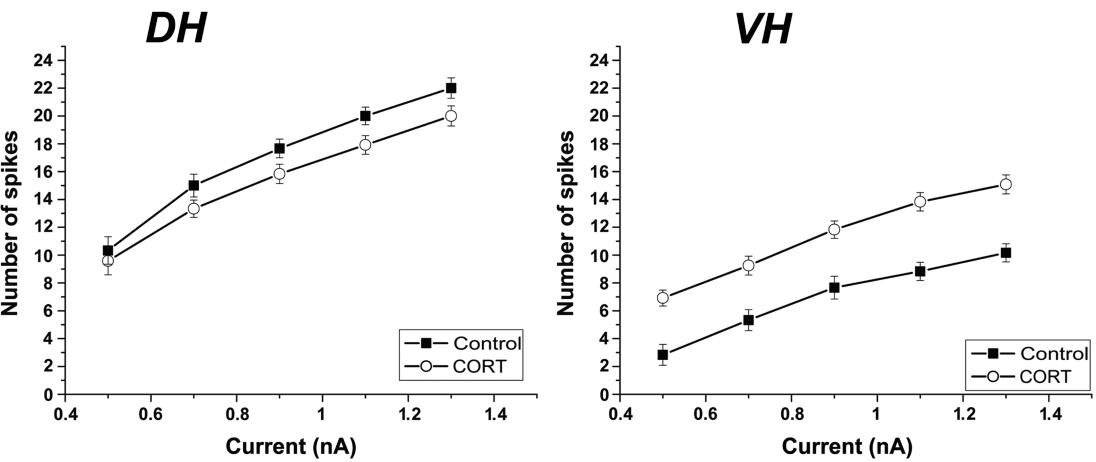

Figure 3. Action potential discharges of $\mathrm{CA} 1$ pyramidal neurons in $\mathrm{DH}$ and $\mathrm{VH}$ before and following exposure to corticosterone. $A$, Representative traces show that injections of same current steps (inset) evoked different responses in CA1 pyramidal neurons of $\mathrm{DH}$ and $\mathrm{VH}$ following treatment with $100 \mathrm{~nm}$ Cort. $\boldsymbol{B}$, Spike rates of CA1 pyramidal neurons increased in VH following treatment with Cort. The number of spikes is expressed as a function of current command.

ing a recording included $V_{\mathrm{m}}$ of at least $-58 \mathrm{mV}$ and series resistance of $<60 \mathrm{M} \Omega$ and membrane capacitance of $60 \mathrm{pF}$, which were not changed significantly throughout the recording session. Signals were amplified with Axopatch 200A and recorded with PClamp-9 (Axon Instruments).

Spontaneous IPSCs (sIPSCs) were recorded by perfusing the slices with DNQX and clamping neurons at $-60 \mathrm{mV}$ using a CsCl-based intracellular solution, to produce large inward currents that reversed at $\sim 0$ $\mathrm{mV}$. Bicuculline $(20 \mu \mathrm{M})$ reliably blocked these currents. TTX $(1 \mu \mathrm{M})$ was added to record miniature IPSCs (mIPSCs). Routinely, 7 min epochs of recordings were stored so as to accumulate sufficient IPSCs or mIPSCs for analysis. Evoked IPSCs were obtained by stimulating stratum oriens with a bipolar nichrome electrode using a Master 8 pulse stimulator (A.M.P.I.), while simultaneously recording from pyramidal neurons in CA1.

Analysis. The electrophysiological data were summarized and analyzed off-line using Clampfit 8 and Origin (Microcal Software). Comparisons among groups were made using different $t$ tests or ANOVA, followed by Tukey's comparisons, as the case may be. Data are shown as mean \pm SEM. For IPSCs and mIPSCs analysis, recordings were filtered and analyzed off-line using MiniAnalysis software (Synaptosoft) with a detection threshold of $7 \mathrm{pA}$. Noise analysis was performed on unfiltered data, $1 \mathrm{~s}$ recording epochs, using the RMS measurements in the noise analysis tool of MiniAnalysis program. This algorithm measures the root-meansquare noise level, and it was performed on a recording window that did not include any visible IPSCs.

\section{Results}

Membrane properties of neurons in the $\mathrm{DH}$ and $\mathrm{VH}$

For the initial comparison of basic properties of neurons from the $\mathrm{DH}$ and $\mathrm{VH}, 12$ neurons were recorded and analyzed in current- clamp mode. The neurons were selected for patch recording based on their gross morphology, location in the pyramidal layer, and having an apical dendrite that extends into stratum radiatum. Several additional neurons that were loaded with a fluorescent dye and later reconstructed on a confocal microscope did not reveal a major difference in cell morphology between the two sectors (data not shown). The mean resting membrane potential was about the same in the two groups (Table 1) as was the input resistance, measured from a slope of voltage deflections to small current pulses, not exceeding $15-20 \mathrm{mV}$ from rest. The difference in membrane time constant $(\tau)$ was small but significantly different between the two groups, being 25 $\mathrm{ms}$ in $\mathrm{VH}$ and $29 \mathrm{~ms}$ in $\mathrm{DH}$ neurons (Table 1) $(p<0.01)$. Firing threshold, measured as the minimum voltage deflection producing an action potential, was strikingly different between the two groups, being $-34.6 \mathrm{mV}$ in the $\mathrm{VH}$ group and $-42 \mathrm{mV}$ in the DH group. While the size of action potentials was the same in both groups, the DH cells discharged significantly more action potentials for the same depolarization than the VH cells (Fig. 2B) (a $500 \mathrm{~ms}, 0.7$ nA current pulse produced $15.7 \pm 0.58$ spikes for $\mathrm{DH}$ and $5.1 \pm 0.63$ for $\mathrm{VH}, p<$ 0.001 ; for a $1.3 \mathrm{nA}$ current pulse, there were $21.7 \pm 0.59$ spikes for $\mathrm{DH}$ and $8.8 \pm$ 0.7 for $\mathrm{VH}, p<0.001)$.

\section{Effects of corticosterone on membrane} properties of neurons in the $\mathrm{DH}$ and $\mathrm{VH}$

The effects of $100 \mathrm{~nm}$ Cort on passive and active membrane properties were compared in $\mathrm{DH}$ and $\mathrm{VH}$ neurons. Separate groups of 6 cells (controls) and 12 cells (treated) were recorded in the two hippocampal regions. In the $\mathrm{DH}$, Cort did not affect resting membrane potential (Table 2), but it did reduce input resistance by $16 \%(p<0.01)$. In addition, membrane time constant was reduced from $29.7 \mathrm{~ms}$ to $12.7 \mathrm{~ms}(p<0.001)$. These results indicate that in the presence of Cort the $\mathrm{DH}$ neurons are leakier. On the other hand, action potential properties, including spike threshold and number of action potential discharges to $500 \mathrm{~ms}$ depolarizing current pulses did not change after exposure to corticosterone $[0.7 \mathrm{nA}$ current pulse produced $15 \pm 0.81$ spikes in control (Ct, $n=6$ cells) and $13 \pm 0.81$ in treated neurons $(n=12$ cells, $p=0.13$ ) (Fig. 3)].

In contrast, the passive properties, resting membrane potential, input resistance, and membrane time constant, did not change in VH neurons from exposure to Cort (Table 3). However, spike thresholds were lowered from $-35.8 \mathrm{mV}$ to $-42 \mathrm{mV}$ $(p<0.001)$. Consequently, the number of action potentials discharged to a $500 \mathrm{~ms}, 0.7 \mathrm{nA}$ depolarizing current pulses went up from $5.3 \pm 0.75$ spikes in control VH cells $(n=6)$ to $9.25 \pm 0.67$ spikes ( $n=12$ cells, $p<0.01$ ), and for $1.3 \mathrm{nA}$ current pulse from $10.16 \pm 0.65$ spikes in control $(n=6$ cells $)$ to $15.08 \pm 0.69$ in the treated cells $(n=12, p<0.001)$ (Fig. 3). These results indicate that while Cort slightly decreased excitability of DH neurons, it increased that of $\mathrm{VH}$ neurons. 


\section{Spontaneous inhibitory synaptic currents in DH and VH}

The presence and properties of IPSCs were recorded in neurons, voltage clamped at $-60 \mathrm{mV}$, with CsCl-containing patch pipettes (Fig. 4), which allowed a better control of membrane potential. Recorded in the presence of DNQX, to verify that no excitatory synaptic currents are detected, the reversal potential for the spontaneous IPSCs was $\sim 0 \mathrm{mV}$ (supplemental Fig. 1 , available at www.jneurosci.org as supplemental material). The IPSCs were completely blocked by bicuculline (see below, Fig. 10), indicating that they are mediated by activation of $\mathrm{GABA}_{\mathrm{A}}$ receptors. The frequency of IPSCs was similar in neurons of the two sectors (DH: $78.2 \pm 12$ events in 7 min of recording, $n=11$ cells, and $73.2 \pm 13.0$ events for $\mathrm{VH}, n=11$ cells). On the other hand, the mean amplitude of the IPSCs was (in pA) $24 \pm 2.1$ in the DH, and $17.3 \pm 0.71$ in the $\mathrm{VH}(n=11$ cells in each group, $p<0.01$ ). The mean rise and decay times were not different between the two groups (Fig. $4 C, D$ ).

\section{Effects of corticosterone on IPSCs in the DH and VH}

Comparisons were routinely made between cells in a slice recorded before and those recorded during exposure to corticosterone (Cort). In some cases recordings were made of the same cells continuously, before and during exposure to the drug (see below), and the results were similar. Eleven cells in each group (before and during Cort in the $\mathrm{DH}$ and before and during Cort in the VH, a total of 44 cells) were used for this comparison. For DH, the frequency was the same before and during treatment $(85.8 \pm 6.5$ evens in 7 min for control, $84.2 \pm 2.97$ for treated, $p=0.765)$. Likewise, the rise and decay times were similar before and after treatment (Fig. 5). The most striking effect of Cort was on the amplitude of the IPSCs, being $22.0 \pm 2.13 \mathrm{pA}$ for control, and $35.5 \pm 1.91 \mathrm{pA}$ for treated cells, a $61 \%$ increase $(p<$ $0.01)$. In contrast, the main effect of Cort in VH neurons was on frequency of IPSCs, which was reduced significantly $(p<0.001)$ from $81.7 \pm 3.5$ in control, to $40.75 \pm 2.35$ events in treated cells, a $50 \%$ reduction. The rise and decay times as well as the amplitudes of the IPSCs were not affected by the treatment $(17.4 \pm 0.36$ pA for control vs $19.6 \pm 0.66 \mathrm{pA}$ for the treated cells, $p=0.6$ ) (Fig. 5).

In all of these experiments, Cort was applied by perfusion at a concentration of $100 \mathrm{nM}$. As this concentration might be considered at the high end of the normal range, we exposed a subgroup of cells both in the $\mathrm{DH}$ and the $\mathrm{VH}$ to a lower concentration, 30 nм Cort (supplemental Fig. 2, available at www.jneurosci.org as supplemental material). The results were similar to those of the previous group, as the size of the IPSCs in the DH rose from an average of $24.7 \pm 2.05 \mathrm{pA}$ to $39 \pm 2.5 \mathrm{pA}(p<0.01, n=9$ cells in each group), while the frequency of events did not change. The opposite was seen in the $\mathrm{VH}$, where the amplitude did not change, but the frequency went down from $80.4 \pm 3.5$ to $49.2 \pm$ 3.8 events in the treated cells $(n=9$ cells in each group, $p<0.001)$ (supplemental Fig. 2, available at www.jneurosci.org as supplemental material).
Table 3. Cellular properties of VH neurons before and during exposure to Cort

\begin{tabular}{lrrr}
\hline Parameter & Control $(n=6)$ & Treated $(n=12)$ & $p$ value \\
\hline RMP $(\mathrm{mV})$ & $-57.33 \pm 0.66$ & $-57.67 \pm 0.55$ & 0.721 \\
Input resistance $(\mathrm{M} \Omega)$ & $42.05 \pm 1.03$ & $40.86 \pm 1.14$ & 0.068 \\
$\tau(\mathrm{ms})$ & $26.36 \pm 0.94$ & $23.12 \pm 1.06$ & 0.057 \\
AP threshold $(\mathrm{mV})$ & $-35.85 \pm 0.57$ & $-42.66 \pm 0.91$ & $<0.001$ \\
AP amplitude $(\mathrm{mV})$ & $112.1 \pm 1.29$ & $113.17 \pm 1.74$ & 0.146 \\
AP duration $(\mathrm{ms})$ & $3.35 \pm 0.143$ & $3.90 \pm 0.140$ & 0.077 \\
AP time to peak $(\mathrm{ms})$ & $0.116 \pm 0.009$ & $0.095 \pm 0.004$ & 0.052 \\
\hline
\end{tabular}

Figure 4. $\quad$ SIPSCS differ between DH and VH. $\boldsymbol{A}, \boldsymbol{B}$, Amplitude $(\boldsymbol{B})$ but not frequency $(\boldsymbol{A})$ of sIPSCs significantly differed between DH and VH ( $p<0.01, n=11$ cells per each group). Representative traces are illustrated on top. C, $\boldsymbol{D}$, IPSC rise times $(\boldsymbol{C})$ and decay times (D) did not differ between the two regions. $\boldsymbol{E}$, Cumulative histograms of sIPSC amplitudes in DH and VH.

\section{Corticosterone pharmacology in the $\mathrm{DH}$}

The receptor types activated by Cort in either DH (Fig. 6) or VH (Fig. 7) were tested using specific MR and GR agonists and antagonists. All of the experiments were conducted with groups of 11 cells and each was examined only once with one ligand or control condition. Each receptor type was examined using a specific agonist (Aldo for MR and Dexa for GR) as well as by exposure to Cort in presence of an MR (spironolactone) or GR (RU38486) antagonist. In the $\mathrm{DH}$, none of the treatments resulted in changes in rise or decay time constants, as seen before. Likewise, the frequencies of IPSCs were not different in the different groups (70.4 \pm 3.7 for control, $66.5 \pm 2.56$ for Aldo, $65.7 \pm 2.4$ for RU + Cort, $76.2 \pm 2.5$ for Dexa, $73.9 \pm 3.1$ for Spiro + Cort $).$ On the other hand, the average amplitude of the IPSCs was strikingly different among the groups [25.7 $\pm 1.4 \mathrm{pA}$ for control, $24.4 \pm 0.6$ for Aldo, $22.2 \pm 0.5$ for RU+Cort, $42.6 \pm 0.82$ for Dexa, $40.3 \pm$ 1.42 for Spiro+Cort; ANOVA $\left(F_{(4,4634)}=888.6, p<0.0001\right)$, followed by post hoc Tukey test, revealed a highly significant $(p<$ $0.0001)$ difference among all groups except between control and $\mathrm{RU}+$ Cort $(p<0.05)$ and control and aldosterone], indicating that activation of GR causes a large increase in IPSCs, whereas activation of MR has no significant effect on IPSCs in the DH.

\section{Corticosterone pharmacology in the $\mathrm{VH}$}

Activation of Cort receptors in the $\mathrm{VH}$ produced different effects from those in the DH. Once again, the rise and decay times were not different in the different groups (Fig. 7). Activation of MRs 
DH

VH

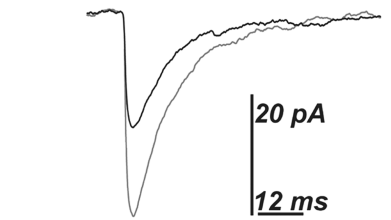

Control

VIIIS Cort $100 \mathrm{nM}$
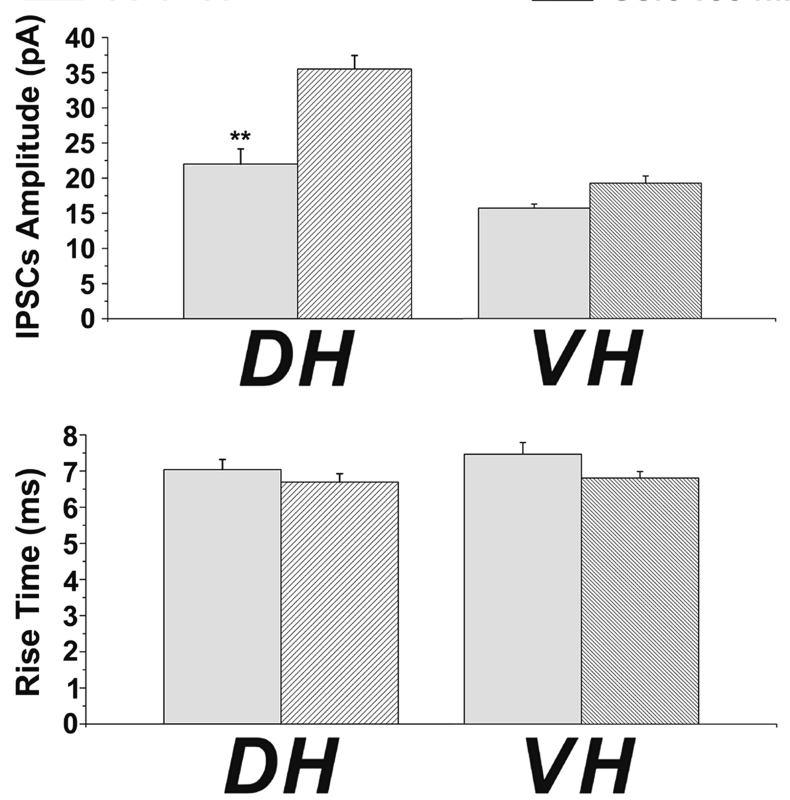
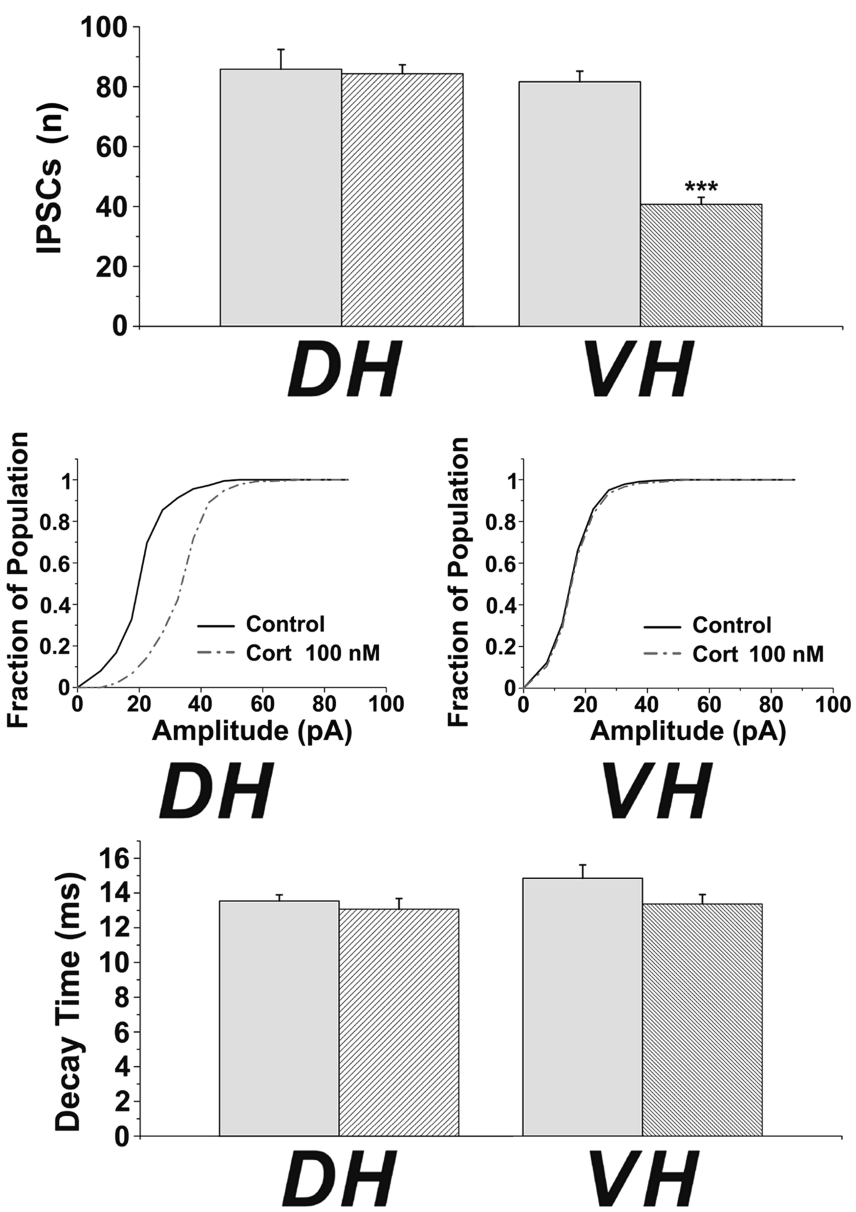

Figure 5. Cort affects sIPSCs differently in DH and VH. In DH, Cort significantly ( $p<0.01, n=11$ cells in each group) increased sIPSC amplitude, without affecting frequency or rise and decay times. Representative traces are shown on top left. In VH, the same concentration of Cort did not affect the amplitude (cumulative histogram at bottom right) or rise and decay times, while it significantly ( $p<0.001, n=11$ cells in each group) attenuated the frequency of sIPSCs (top right, $n=$ number of events in 7 min of recording epoch). Representative traces are shown on top left.

caused a reduction in frequency of IPSCs from $72.3 \pm 2.16$ events in control to $54.4 \pm 3.06$ for aldosterone and $54.1 \pm 2.6$ for $\mathrm{RU}+$ Cort, but there was no change in cells exposed to Dexa $(73.2 \pm 3.2)$ or Spiro + Cort $(73.4 \pm 2.38)$. ANOVA revealed a significant difference $\left(F_{(4,60)}=14.4, p<0.0001\right)$ among all groups with aldosterone and RU + Cort. In striking contrast, the mean amplitude changed from $17.48 \pm 0.52$ for control, $18.0 \pm$ 1.14 for aldosterone, and $16.21 \pm 0.81$ for RU+Cort to $33.3 \pm$ 0.75 for Dexa and $34.31 \pm 0.43$ for Spiro+Cort [ANOVA $\left(F_{(4,4250)}=1186.7, p<0.0001\right)$ and post hoc Tukey test revealed a significant difference between the control, Aldo, and RU+Cort groups and the Dexa and Spiro+Cort groups], indicating that activation of MR caused a reduction in IPSC frequency, while activation of GR in both the $\mathrm{VH}$ and the $\mathrm{DH}$ caused a large increase in IPSC amplitudes. Such an effect was not seen in response to Cort alone (Fig. 5).

To identify possible mechanisms underlying the action of Dexa to increase IPSC size, and Aldo to decrease IPSC frequency, the following experiments were conducted. In the first, we examined whether the change in size of IPSC is not a trivial consequence of a change in GABA reversal potential. While it is unlikely that a change in $\mathrm{Cl}$ distribution will take place when the ion is clamped via the patch pipette, there might be some technicalities that may affect reversal potential after exposure to the steroid hormone (e.g., a change in access resistance). This was not the case, as the reversal potential was the same and only the slope was higher after Dexa (supplemental Fig. 1, available at www.jneurosci.org as supplemental material) (tested in nine cells before and shortly after treatment with Dexa), indicating that the amplitude of the IPSC reflects a genuine change in postsynaptic $\mathrm{GABA}_{\mathrm{A}}$ receptor conductance.

A second experiment examined the possibility that the change in IPSC amplitude is likely to be mediated by a membrane receptor rather than a nuclear receptor, which required more time to be established. In this experiment, the $\mathrm{DH}$ slices were perfused transiently with a high $(100 \mathrm{nM})$ or a low $(30 \mathrm{nM})$ concentration of Dexa. A rapid, membrane effect is expected to take place within 3-6 min after onset of exposure to the drug (the time needed to reach maximal concentration of the drug in the slice is $6 \mathrm{~min}$ ). It did not (Fig. 8); the first significant change in IPSC amplitude was seen 25 min after onset of perfusion of Dexa, and in fact, 10 min after the drug was already washed out. The effect of Dexa continued to grow until 55 min after onset of drug perfusion. This indicates that Dexa action is not likely to involve a rapid membrane effect.

A third experiment examined the likelihood that Dexa effect is mediated by a neurosteroid, known to modulate GABA neurotransmission. For these experiments $(n=9$ cells) the slices were perfused with a neurosteroid antagonist finasteride $(1 \mu \mathrm{M})$ for 10 min before being exposed to Dexa (supplemental Fig. 3, available at www.jneurosci.org as supplemental material). Under these conditions Dexa was still able to produce a $60 \%$ increase in IPSC 
amplitudes as in control cells. These experiments indicate that Dexa is acting on a genuine GR to produce a long-lasting increase in IPSC magnitude.

Effects of dexamethasone on mIPSC and GABA noise

The effect of GR on size of IPSCs can reflect a presynaptic locus of action, to increase synchronized action potentialinduced release of GABA, an effect on GABAergic neuron firing properties, or an effect on postsynaptic GABA receptor currents. To examine these possibilities we recorded spontaneous miniature inhibitory synaptic currents (mIPSCs), in presence of TTX and the glutamate receptor antagonists. Under these conditions, no presynaptic action potential is relevant to the observed change, and an increase in mIPSC amplitude is taken to indicate a synaptic locus of action. In the same series of experiments we exposed the slice to a low concentration of GABA ( $5 \mu \mathrm{M})$, which, upon a continuous perfusion produced a $30-40$ pA inward current which recovered slowly, and caused an increase in membrane noise (Fig. 9). The addition of GABA to the perfusion medium caused a large increase in mIPSC amplitudes and frequencies and prolonged their decay time (Fig. 9A, $n=6$ cells, $F_{(2,17)}=30.0, p<$ $0.05)$. A similar effect was seen when the slice was perfused with the GABA-T antagonist, $\gamma$-vinyl-GABA (GVG), which causes accumulation of GABA at the synapse (Engel et al., 2001) (Fig. 9B, $n=6$ cells, $F_{(2,17)}$ $=101.2, p<0.05)$.

In the presence of GABA, Dexa caused an even larger increase in mIPSC amplitudes, both in $\mathrm{DH}$ and $\mathrm{VH}$ neurons (Fig. 10). In DH, two-way ANOVA revealed a significant difference between groups $\left(F_{(1,38)}=60.1, p<0.0001\right)$, and post hoc $t$ test showed a statistically significant difference both between control and Dexa ( $p<$ 0.01 ) and between control/GABA and Dexa $(p<0.0001)$. A two-way ANOVA also revealed a significant difference between treatment $\left(F_{(1,38)}=170.4, p<\right.$ $0.0001)$ with a post hoc $t$ test at the significance level of $p<0.0001$. The interaction between group and treatment was also significant $\left(F_{(1,38)}=38.4, p<0.0001\right)$. In $\mathrm{VH}$, two-way ANOVA revealed a significant difference between groups $\left(F_{(1,32)}=\right.$ $660.8, p<0.0001)$, and post hoc $t$ test showed a statistical significance for both control and Dexa $(p<0.001)$ and control/ GABA and Dexa/GABA $(p<0.0001)$. A two-way ANOVA also revealed a significant difference between treatment $\left(F_{(1,32)}\right.$ $=183.2, p<0.0001)$ with a post hoc $t$ test

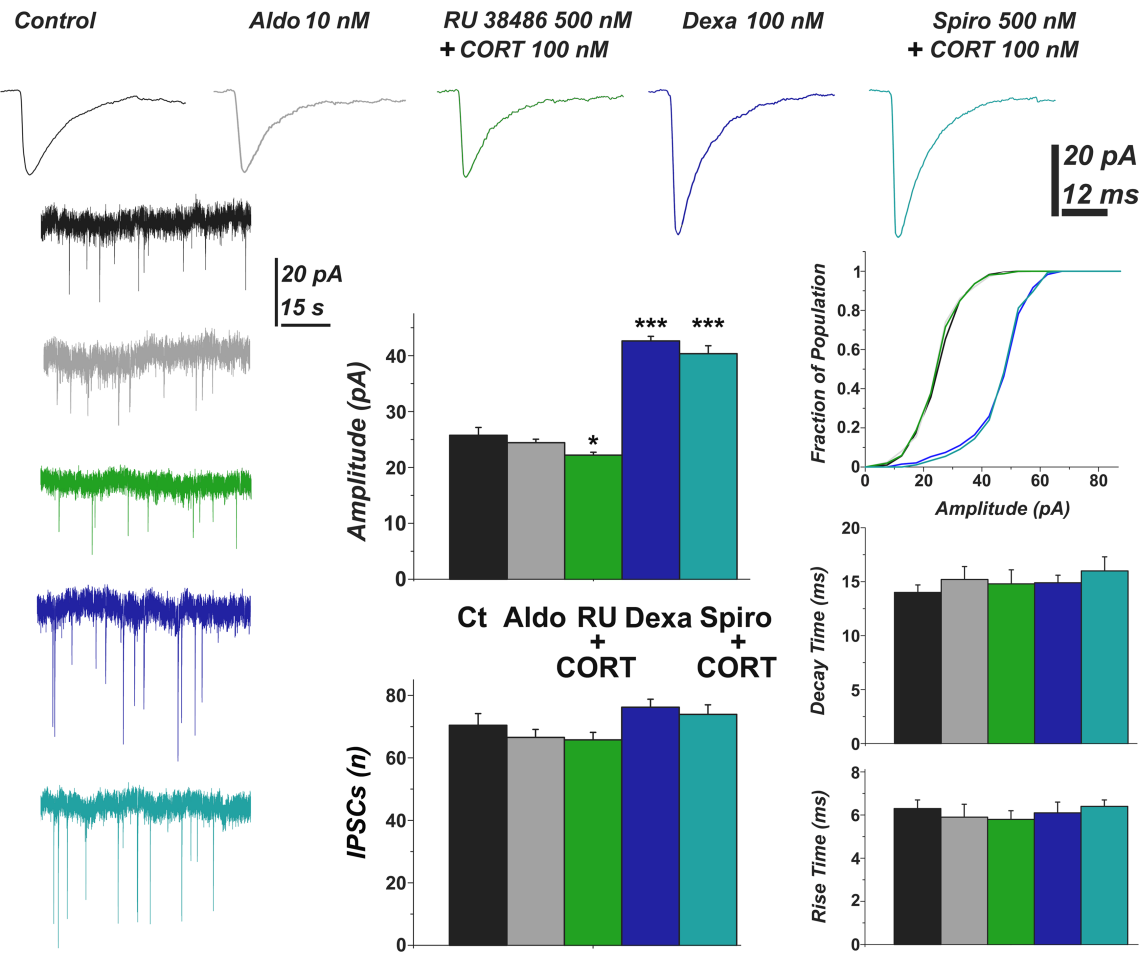

Figure 6. GRactivation increases sIPSC amplitude in DH. Activation of GRs by Dexa ( $100 \mathrm{~nm}$ ) or Cort ( $100 \mathrm{~nm}$ ) plus Spiro ( $500 \mathrm{~nm}$ ), to block MR, mimicked the increase in sIPSC amplitude mediated by Cort in the DH. Activation of MRs by Aldo (10 nm) or Cort (100 nm) plus RU ( $500 \mathrm{~nm}$, to block GR) did not affect either amplitude or frequency of sIPSCs in the DH. Rise and decay times of sIPSCS were not affected by either MR or GR activation in the DH. Representative traces are shown on top, and slow records are on the left, color coded for the different groups. $n=11$ cells per each group. Significance level is calculated from ANOVA followed by Tukey's comparisons.

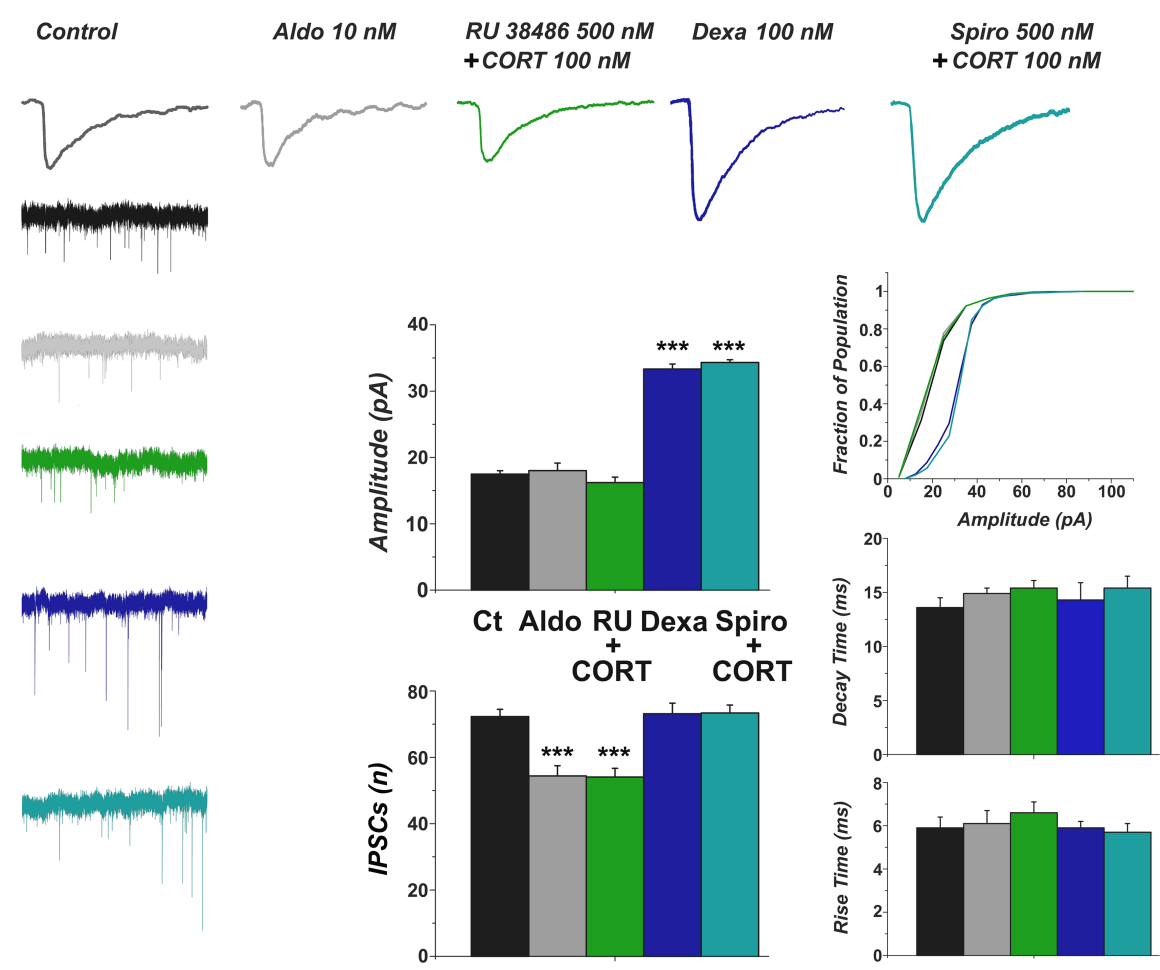

Figure 7. MR activation and GR activation differently affect sIPSC in VH. In VH, activation of GRs by Dexa (100 nM) or Cort (100 nм) plus Spiro ( $500 \mathrm{~nm}$ ) significantly increased sIPSC amplitude, while activation of MRs by Aldo (10 nm) or RU (500 nm) plus Cort (100 nM) significantly suppressed sIPSC frequency. Rise and decay times of sIPSCs were not affected by either MR or GR activation. Representative traces are shown on top, and slow records are on the left, color coded for the different treatments. $n=11$ cells per each group. Refer to the text for significance level. 

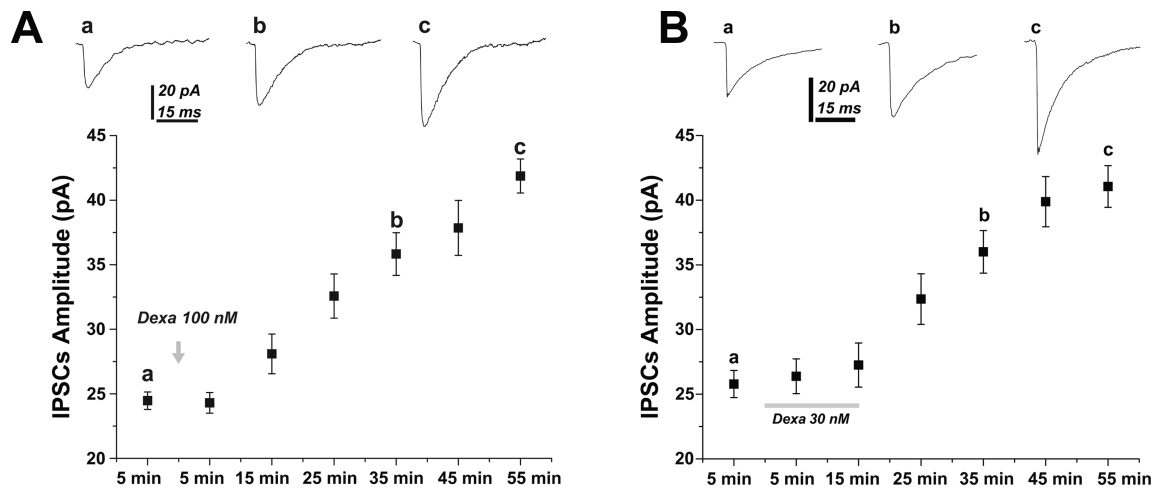

Figure 8. Slow onset of Dexa effects on sIPSC amplitude in DH. Clamping neurons for $>1 \mathrm{~h}$ showed that Dexa (100 nм) $(\boldsymbol{A})$ changes sIPSC amplitude following 35 min of continuous application of the drug ( $p<0.001, n=10$ cells; 5 min before Dexa application, $24.46 \pm 0.67 \mathrm{pA} ; 35 \mathrm{~min}$ after $100 \mathrm{~nm}$ Dexa application, $35.82 \pm 1.66 \mathrm{pA}$ ). $\boldsymbol{B}$, A short application (15 min) of $30 \mathrm{~nm}$ Dexa mimicked the effect of the continuous application of the higher dose of the steroid, illustrating that the onset of the effect is rather slow, starting $25 \mathrm{~min}$ after onset of drug administration, at the time that the drug is already washed out ( $3-6 \mathrm{~min}$ for washin and washout) (5 min before Dexa application, $25.78 \pm 1.04 \mathrm{pA} ; 35$ min after 15 min application, $36.00 \pm 1.55 \mathrm{pA} ; n=10$ cells, $p<0.001)$. Representative traces $(a, b, c)$ at indicated times are shown on top.
A

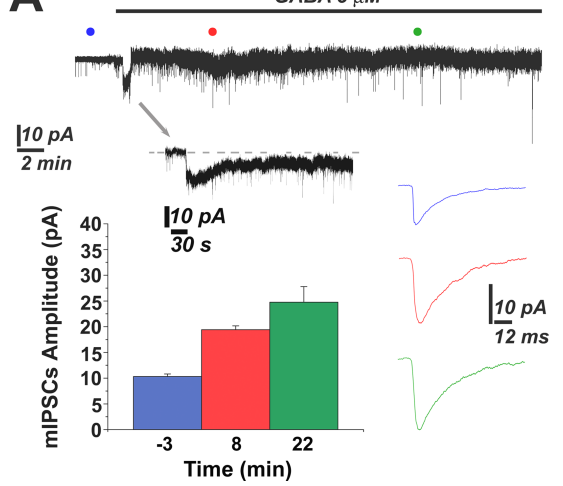

B

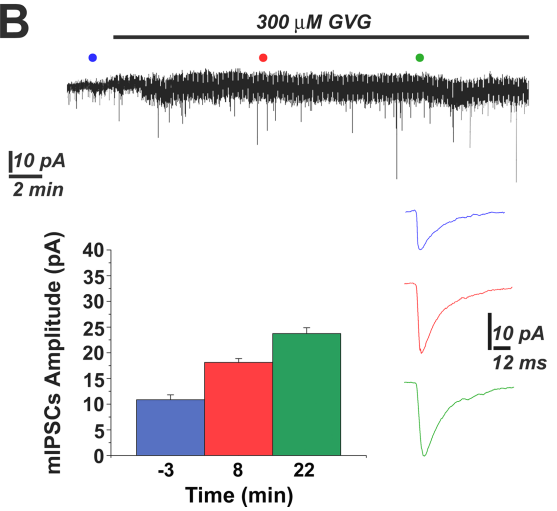

Figure 9. Persistent exposure to low GABA levels increase mIPSC amplitude in CA1 pyramidal neurons. Neurons were voltage clamped at $-60 \mathrm{mV}$ and exposed continuously to $5 \mu \mathrm{m} \mathrm{GABA}(\boldsymbol{A})$ or $300 \mu \mathrm{M} \mathrm{GVG}(\boldsymbol{B})$ in the presence of TTX and DNQX. Expanded trace below shows the first few minutes after onset of exposure to GABA, demonstrating slowly decaying inward current. № similar current was seen in response to GVG. The data were analyzed in 3 min epochs before (blue) and 8 min (red) and 22 min (green) after onset of GABA (or GVG) perfusion. Sample records are depicted on the right; mean mIPSC amplitudes are shown below.

at the significance level of $p<0.0001$. The interaction between group and treatment was also significant $\left(F_{(1,32)}=392.3, p<\right.$ $0.0001)$. Surprisingly, the GABA induced increase in membrane noise was suppressed by Dexa, once again in both $\mathrm{DH}$ and $\mathrm{VH}$. In $\mathrm{DH}$, a $2 \times 3$ ANOVA detected an overall significant group effect $\left(F_{(1,54)}=32.3, p<0.0001\right)$ with a post hoc $t$ test revealing a significant effect only between Ct/GABA and Dexa/GABA $(p<$ $0.0001)$. In addition, the analysis showed that there is a significant effect of treatment $\left(F_{(2,54)}=135.4, p<0.0001\right)$ regardless of the different groups with a post hoc Tukey test revealing a significant difference $(p<0.0001)$ between all the treatments besides the control and bicuculline. A significant interaction between groups and treatment was also found $\left(F_{(2,54)}=19.9, p<0.0001\right)$. In VH, a $2 \times 3$ ANOVA detected an overall significant group effect $\left(F_{(1,48)}=19.5, p<0.0001\right)$ with a post hoc $t$ test revealing a significant effect only between Ct/GABA and Dexa/GABA $(p<$ 0.001 ). In addition, the analysis showed that there is a significant effect of treatment $\left(F_{(2,48)}=105.1, p<0.0001\right)$ regardless of the different groups with a post hoc Tukey test revealing a significant difference $(p<0.0001)$ between all the treatments. A significant interaction between groups and treatment was also found $\left(F_{(2,48)}\right.$
$=14.8, p<0.0001)$. This indicates that Dexa has a dual effect, to increase mIPSC size, and to reduce the nonsynaptic GABA-mediated sustained inhibition. Whether these two effects of Dexa are related to each other, i.e., that Dexa causes a shift of $\mathrm{GABA}_{\mathrm{A}}$ receptors from nonsynaptic to synaptic locations is subject for further investigation.

Finally, the functional relevance of the moderate decrease in spontaneous IPSC produced by activation of the MRs in the $\mathrm{VH}$ is not entirely clear. To address this issue more directly, we resorted to the analysis of IPSCs evoked by afferent stimulation in the hippocampal slices. IPSCs were evoked by electrical stimulation of stratum oriens, near the recorded neuron in the pyramidal layer. Excitatory afferent activity was blocked by a combination of DNQX and APV. Under these conditions, we could generate a stimulus intensitydependent short latency IPSC both in DH and $\mathrm{VH}$ slices. The latencies and rise and decay times of the evoked IPSCs were similar for both $\mathrm{DH}$ and $\mathrm{VH}$, before and after treatment with Aldo (Fig. 11). A second stimulation, applied $50 \mathrm{~ms}$ after the first one, produced a large potentiation of the response, both in $\mathrm{DH}$ and $\mathrm{VH}$ cells (Fig. $11 B)$. Interestingly, the initial responses to the stimulation, as well as the potentiated responses were larger in $\mathrm{DH}$ than in $\mathrm{VH}$ cells (Fig. 11C). Aldo had no effect on the response to the first stimulus in either region (Fig. 11C), but it caused a marked suppression of the response to the second stimulus (Fig. $11 B, D$ ). This effect was more striking in the $\mathrm{VH}$, where the potentiation seen in the control condition was converted into a depression of the response to the second response relative to the first one. A two-way ANOVA revealed that there is a significant difference between groups $\left(F_{(1,32)}=328.9, p<0.0001\right)$ and between treatment $\left(F_{(1,32)}=88.1, p<0.0001\right)$. Specifically post hoc $t$ test for treatment showed that there is a significant difference between DH and VH before ( $p<0.0001$, control) and after treatment with Aldo $(p<0.0001)$. These results indicate that the effects of aldosterone are likely to be mediated by reducing facilitation of reactivity to the second stimulation in a pair. This also indicates that, stimulated at a rate of at least $20 \mathrm{~Hz}$, the postsynaptic inhibition is likely to be less effective in aldosterone-treated hippocampal slices, and that this effect is more pronounced in $\mathrm{VH}$ than in $\mathrm{DH}$.

\section{Discussion}

In the present study we identified two types of unique actions of corticosterone on IPSCs recorded from CA1 neurons in slices of the dorsal and ventral hippocampus. The first one, involving a large, $60 \%$ increase in the magnitude of spontaneous IPSC, as well as a similar increase in the size of MIPSCs, indicating a synaptic locus of action, is mediated by activation of a GR, primarily in the DH. This is a slowly developing response, detected within 
$30-45 \mathrm{~min}$ after onset of the steroid application, hence it cannot be ruled out that it is mediated by a genomic receptor.

Interestingly, the increase in size of the mIPSCs was correlated with a reduction in membrane noise produced in response to the continuous application of a low concentration of GABA, which activates primarily nonsynaptic $\mathrm{GABA}_{\mathrm{A}}$ receptors. It is tempting to speculate that the increase in mIPSC amplitude results from diffusion of nonsynaptic $\mathrm{GABA}_{\mathrm{A}}$ receptors into the synapse, hence their depletion from nonsynaptic regions of the membrane. However, there are two problems with this interpretation. First, the composition of $\mathrm{GABA}_{\mathrm{A}}$ subunits is different in synaptic and nonsynaptic sites; the former are composed of $\alpha 1, \alpha 2$, or $\alpha 3$ subunits, whereas the extrasynaptic receptors are composed of $\alpha 4-\alpha 6$ subunits (Jacob et al., 2008). Second, the IPSC response to corticosterone develops slowly, whereas an action that reflects diffusion of receptors in membrane is expected to be rather fast. Still, the relationship between the synaptic and nonsynaptic GABA responses to steroid action needs further investigation.

The second response, mediated by activation of $M R$, involves a reduction in the frequency but not the amplitude of IPSC. It is found primarily in the $\mathrm{VH}$, and may reflect an effect at the presynaptic GABAergic terminals. In support of this assumption is the marked reduction in paired-pulse facilitation of IPSCs seen in response to the MR agonist aldosterone, indicating that a calcium-dependent recruitment of release from presynaptic terminals may be impaired by the steroid.

Such a presynaptic, MR-mediated response can contribute to the enhanced excitability of $\mathrm{VH}$ neurons, in that a train of afferent stimulation, which activates both excitatory and inhibitory (feedforward and feedback inhibition) synapses, will now produce a smaller accumulating IPSC, and consequently a larger depolarization, leading to activation of voltage-gated calcium channelmediated LTP, as suggested before (Maggio and Segal, 2007b). In this way, even though the individual IPSCs are not changed much by MR, their lack of recruitment following exposure to MR is the major factor that will enable enhancement of LTP (Bliss and Collingridge, 1993). This effect is similar, but milder in the $\mathrm{DH}$, and is masked by an increase in the size of IPSCs, produced by activation of GRs.

The current results are partly consistent with previous results obtained with slices taken from the (most likely dorsal) hippocampus. It has been previously shown, in pyramidal cells recorded with sharp micropipettes, that corticosterone reduces excitability of hippocampal neurons, as well as reduces EPSPs and slow IPSPs (Joëls and de Kloet, 1993). A later inability to fully replicate these results while recording with patch pipettes led to the suggestion that the presence of cytosolic factors contribute to this reduction in synaptic potentials, and that these factors are likely to be washed away when a patch pipette is used to record intracellular activity (Teschemacher et al., 1996). Being aware of this problem, we compared recordings made from different groups of neurons in absence and presence of the steroid hormone, with neurons that were continuously recorded across $30-55 \mathrm{~min}$ before and after exposure to the drugs. We found very similar results, indicating that the patch pipette, in our hands, does not wash out the factors that are necessary for production of the effects of corticosterone on synaptic responses. It is possible that the washout of the cytosolic factors is relevant with respect to the slow IPSPs recorded before, and not to the fast $\mathrm{GABA}_{\mathrm{A}}{ }^{-}$ mediated IPSCs, recorded herein. Interestingly, a more recent publication (Verkuyl et al., 2005) reports that a high concentration of corticosterone, likely to activate GRs, reduced the frequency but not the amplitude of mIPSCs in the rat paraventricular nucleus of the hypothalamus, as well as reduced the amplitude of evoked paired-pulse inhibitory response. These results are similar to the ones we observed herein, except that they are assumed to be mediated by activation of GRs.

One plausible hypothesis to explain these different results in the different studies could be that a different distribution of MRs and GRs exists in DH versus VH. Specifically, more MRs are assumed to be present in the $\mathrm{VH}$, while the $\mathrm{DH}$ is likely to contain more GRs. Accordingly, a high dose of corticosterone should 


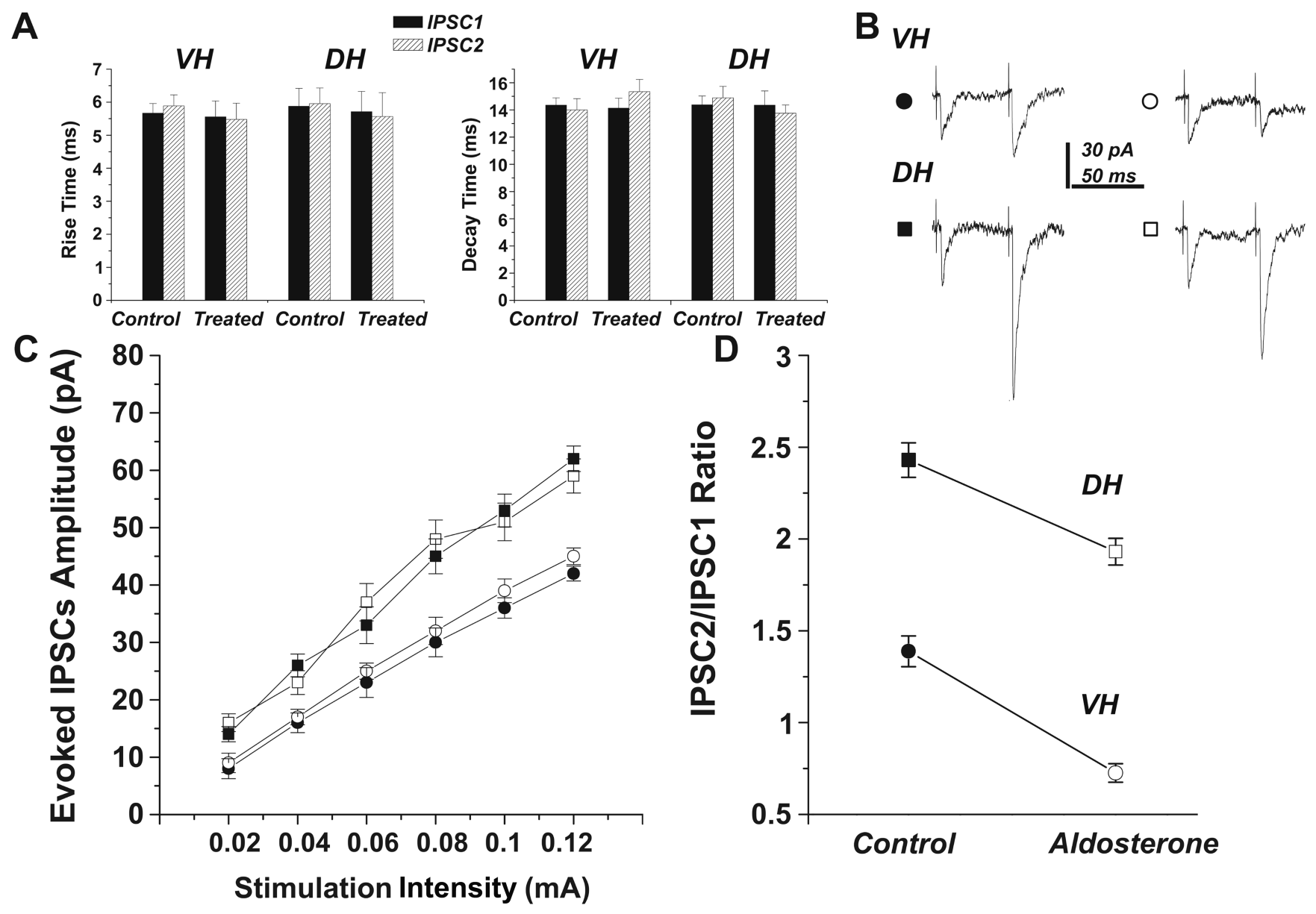

Figure 11. MR activation affects evoked paired-pulse response differently in DH and VH. Aldosterone decreased evoked paired-pulse facilitation of IPSCs in DH, while it converted the facilitation to inhibition in VH. $\boldsymbol{A}$, Rise and decay time of the evoked IPSCs were the same in DH and VH, in both control and treated slices. $\boldsymbol{B}$, Paired-pulse facilitation in both the VH and the DH demonstrate strong facilitation of the response to the second pulse. Following treatment with Aldo (open circle and square), the facilitation is much reduced or abolished. C, Input- output curves for single evoked IPSCS showed a slight difference in evoked responses between DH and VH, as seen before for sIPSCs (Fig. 2), that was not affected by treatment with aldosterone, as seen before for sIPSCs. D, Paired-pulse responses are reduced in presence of aldosterone in the $\mathrm{DH}$ but are converted to inhibition in the $\mathrm{VH}$.

activate more easily GRs in the DH, while MRs should be activated in $\mathrm{VH}$ at the same concentration. This hypothesis is supported by a recent study (Robertson et al., 2005) that suggests that in a normal animal not exposed to stress, the basal level of MRs in $\mathrm{VH}$ is double that of the $\mathrm{DH}$ while the basal level of GRs is twice as high in $\mathrm{DH}$ than in $\mathrm{VH}$.

It has been reported that corticosteroids trigger two types of responses: a genomic and a nongenomic (de Kloet et al., 1996; Smythe et al., 1997; Yamada et al., 2003; Karst et al., 2005; Karst and Joëls, 2005). The first one is slow, is mediated by intracellular corticosteroid receptors, and involves protein synthesis. The second one is mediated by membrane-bound receptors, does not require protein synthesis, and is considered to be a fast response. In our previous studies, aldosterone-promoted LTP was blocked by an Erk antagonist, indicating the involvement of a membrane receptor, consistent with the suggestion that MAP kinases mediate fast corticosterone membrane-bound receptor-induced signaling (Yang et al., 2004; Chai et al., 2005). Such an MR action is assumed to underlie a presynaptic increase in mEPSC produced by corticosterone in CA1 hippocampal neurons (Olijslagers et al., 2008). This effect is different from our observed reduction in mIPSC frequency, produced by activation of a MR in the $\mathrm{VH}$, but it serves the same purpose, i.e., to increase excitability of the $\mathrm{VH}$ and enable the production of a larger LTP under certain conditions.
In addition to the difference in IPSC amplitudes between $\mathrm{DH}$ and $\mathrm{VH}$ neurons, pyramidal neurons in the two sectors of the hippocampus also vary considerably in firing threshold, as well as in the number of action potentials discharged in response to a similar depolarizing command. This difference contributes to the higher excitability of DH neurons, compared with those from the VH. The higher excitability may also contribute to the larger LTP found in this sector, as these neurons may allow a larger influx of calcium into the neuron following tetanic synaptic activation. On the other hand, the lower LTP in the $\mathrm{VH}$ indicates that this region is amenable to more intense regulation by metaplastic stimuli, including stress, monoamines, and other neuromodulators. The lower IPSC amplitudes and lower paired-pulse facilitation of IPSCs, in the absence of corticosterone, may also explain the higher sensitivity of the VH to epileptic seizures.

One serendipitous finding is related to the effects of GABA on IPSCs. In previous studies (Thompson and Gähwiler, 1989, Overstreet et al., 2000) a brief exposure to GABA caused a transient reduction in IPSC amplitudes. These experiments used puff or iontophoretic application of GABA or the GABA agonist muscimol, and studied either neurons in dissociated form or dentate granule cells in cultured slices. Our results were obtained with acute slices of CA1 region, exposed to GABA or GVG by slow perfusion. GABA as well as GVG produced a slow increase in mIPSCs, as seen before with GVG, which blocks GABA-T and 
causes accumulation of GABA at the synapse (Engel et al., 2001). It is likely that the difference between our results and those of Overstreet et al. (2000) stems from the different cell and synapse types, as indicated in the difference in initial mIPSC amplitudes, but these issues are subject to further experimentation.

Finally, the behavioral consequence of differential modulation of IPSC is complex indeed. We have demonstrated that corticosteroids differentially modulate IPSCs along the septotemporal axis of the hippocampus. It has been shown that blocking MRs (Smythe et al., 1997) lowers anxiety levels in vivo. On the other hand, we have shown that MRs are specifically activated in the VH after stress to enable LTP. Altogether these experiments suggest that MRs' modulation of synaptic transmission in $\mathrm{VH}$ plays an important role in the functionality of the $\mathrm{VH}$ in situations that challenge the homeostatic balance of the animal. The unique efferents of the $\mathrm{VH}$, connecting the hippocampus to the anterior and medial parts of the hypothalamus and to the amygdala (Witter and Amaral, 2004) hint at the possible roles of the altered plasticity of the $\mathrm{VH}$ in the ability of the animal to cope with an acute stress.

\section{References}

Avital A, Segal M, Richter-Levin G (2006) Contrasting roles of corticosteroid receptors in hippocampal plasticity. J Neurosci 26:9130-9134.

Bliss TV, Collingridge GL (1993) A synaptic model of memory: long-term potentiation in the hippocampus. Nature 361:31-39.

Chai W, Garrelds IM, de Vries R, Batenburg WW, van Kats JP, Danser AH (2005) Nongenomic effects of aldosterone in the human heart: interaction with angiotensin II. Hypertension 46:701-706.

Chameau P, Qin Y, Spijker S, Smit G, Joëls M (2007) Glucocorticoids specifically enhance L-type calcium current amplitude and affect calcium channel subunit expression in the mouse hippocampus. J Neurophysiol 97:5-14.

Colgin LL, Kubota D, Jia Y, Rex CS, Lynch G (2004a) Long-term potentiation is impaired in rat hippocampal slices that produce spontaneous sharp waves. J Physiol 558:953-961.

Colgin LL, Kubota D, Brucher FA, Jia Y, Branyan E, Gall CM, Lynch G (2004b) Spontaneous waves in the dentate gyrus of slices from the ventral hippocampus. J Neurophysiol 92:3385-3398.

de Kloet ER, Rots NY, Cools AR (1996) Brain-corticosteroid hormone dialogue: slow and persistent. Cell Mol Neurobiol 16:345-356.

Engel D, Pahner I, Schulze K, Frahm C, Jarry H, Ahnert-Hilger G, Draguhn A (2001) Plasticity of rat central inhibitory synapses through GABA metabolism. J Physiol 535:473-482.

Garcia R (2002) Stress, metaplasticity, and antidepressants. Curr Mol Med 2:629-638.

Jacob TC, Moss SJ, Jurd R (2008) GABAA receptor trafficking and its role in the dynamic modulation of neuronal inhibition. Nat Rev Neurosci 9:331-343.

Joëls M (2008) Functional actions of corticosteroids in the hippocampus. Eur J Pharmacol 583:312-321.

Joëls M, de Kloet ER (1993) Corticosteroid actions on amino acid-mediated transmission in rat CA1 hippocampal cells. J Neurosci 13:4082-4090.

Karst H, Joëls M (2005) Corticosterone slowly enhances miniature excita- tory postsynaptic current amplitude in mice CA1 hippocampal cells. J Neurophysiol 94:3479-3486.

Karst H, Berger S, Turiault M, Tronche F, Schütz G, Joëls M (2005) Mineralocorticoid receptors are indispensable for nongenomic modulation of hippocampal glutamate transmission by corticosterone. Proc Natl Acad Sci U S A 102:19204-19207.

Kim JJ, Yoon KS (1998) Stress: metaplastic effects in the hippocampus. Trends Neurosci 21:505-509.

Kim JJ, Song EY, Kosten TA (2006) Stress effects in the hippocampus: synaptic plasticity and memory. Stress 9:1-11.

Maggio N, Segal M (2007a) Unique regulation of long term potentiation in the rat ventral hippocampus. Hippocampus 17:10-25.

Maggio N, Segal M (2007b) Striking variations in corticosteroid modulation of long-term potentiation along the septotemporal axis of the hippocampus. J Neurosci 27:5757-5765.

Maruki K, Izaki Y, Nomura M, Yamauchi T (2001) Differences in pairedpulse facilitation and long-term potentiation between dorsal and ventral CA1 regions in anesthetized rats. Hippocampus 11:655-661.

Moser MB, Moser EI (1998) Functional differentiation in the hippocampus. Hippocampus 8:608-619.

Olijslagers JE, de Kloet ER, Elgersma Y, van Woerden GM, Joëls M, Karst H (2008) Rapid changes in hippocampal CA1 pyramidal cell function via pre- as well as postsynaptic membrane mineralocorticoid receptors. Eur J Neurosci 27:2542-2550.

Orchinik M, Carroll SS, Li YH, McEwen BS, Weiland NG (2001) Heterogeneity of hippocampal $\mathrm{GABA}_{\mathrm{A}}$ receptors: regulation by corticosterone. J Neurosci 21:330-339.

Overstreet LS, Jones MV, Westbrook GL (2000) Slow desensitization regulates the availability of synaptic $\mathrm{GABA}_{\mathrm{A}}$ receptors. J Neurosci 20:7914-7921.

Papatheodoropoulos C, Kostopoulos G (2000) Decreased ability of rat temporal hippocampal CA1 region to produce long-term potentiation. Neurosci Lett 279:177-180.

Robertson DA, Beattie JE, Reid IC, Balfour DJ (2005) Regulation of corticosteroid receptors in the rat brain: the role of serotonin and stress. Eur J Neurosci 21:1511-1520.

Smythe JW, Murphy D, Timothy C, Costall B (1997) Hippocampal mineralocorticoid, but not glucocorticoid, receptors modulate anxiety-like behavior in rats. Pharmacol Biochem Behav 56:507-513.

Teschemacher A, Zeise ML, Zieglgänsberger W (1996) Corticosteroneinduced decrease of inhibitory postsynaptic potentials in rat hippocampal pyramidal neurons in vitro depends on cytosolic factors. Neurosci Lett 215:83-86.

Thompson SM, Gähwiler BH (1989) Activity-dependent disinhibition. III. Desensitization and GABAB receptor-mediated presynaptic inhibition in the hippocampus in vitro. J Neurophysiol 61:524-533.

Verkuyl JM, Karst H, Joëls M (2005) GABAergic transmission in the rat paraventricular nucleus of the hypothalamus is suppressed by corticosterone and stress. Eur J Neurosci 21:113-121.

Witter MP, Amaral DG (2004) Hippocampal formation. In: The rat nervous system, Ed 3 (Paxinos G, ed), pp 635-693. San Diego: Academic.

Yamada K, McEwen BS, Pavlides C (2003) Site and time dependent effects of acute stress on hippocampal long-term potentiation in freely behaving rats. Exp Brain Res 152:52-59.

Yang CH, Huang CC, Hsu KS (2004) Behavioral stress modifies hippocampal synaptic plasticity through corticosterone-induced sustained extracellular signal-regulated kinase/mitogen-activated protein kinase activation. J Neurosci 24:11029-11034 